\title{
Amino acid secretion influences the size and composition of copper carbonate nanoparticles synthesized by ureolytic fungi
}

\author{
Feixue Liu $^{1} \cdot$ Laszlo Csetenyi $^{2} \cdot$ Geoffrey Michael Gadd ${ }^{1}$ (iD \\ Received: 3 April 2019 / Revised: 31 May 2019 / Accepted: 1 June 2019 / Published online: 9 July 2019 \\ (C) The Author(s) 2019
}

\begin{abstract}
The ureolytic activity of Neurospora crassa results in an alkaline carbonate-rich culture medium which can precipitate soluble metals as insoluble carbonates. Such carbonates are smaller, often of nanoscale dimensions, than metal carbonates synthesized abiotically which infers that fungal excreted products can markedly affect particle size. In this work, it was found that amino acid excretion was a significant factor in affecting the particle size of copper carbonate. Eleven different amino acids were found to be secreted by Neurospora crassa, and L-glutamic acid, L-aspartic acid and L-cysteine were chosen to examine the impact of amino acids on the morphology and chemical composition of copper carbonate minerals. X-ray powder diffraction (XRPD), scanning electron microscopy (SEM), Fourier-transform infrared (FTIR) spectroscopy, thermogravimetric analysis (TGA) and X-ray photoelectron spectroscopy (XPS) were used to characterize the obtained copper carbonate samples. Copper carbonate nanoparticles with a diameter of 100-200 nm were produced with L-glutamic acid, and the presence of L-glutamic acid was found to stabilize these particles in the early phase of crystal growth and prevent them from aggregation. FTIR and TG analysis revealed that the amino acid moieties were intimately associated with the copper mineral particles. Component analysis of the final products of TG analysis of the copper minerals synthesized under various conditions showed the ultimate formation of $\mathrm{Cu}, \mathrm{Cu}_{2} \mathrm{O}$ and $\mathrm{Cu}_{2} \mathrm{~S}$, suggesting a novel synthesis method for producing these useful $\mathrm{Cu}$-containing materials.
\end{abstract}

Keywords Fungi $\cdot$ Biomineralization $\cdot$ Copper carbonate $\cdot$ Nanoparticles $\cdot$ Amino acids

\section{Introduction}

Copper nanoparticles have been considered as a viable alternative to gold and silver nanoparticles due to lower cost, higher natural abundance and comparable electrical and thermal conductivity (Dabera et al. 2017; Kimber et al. 2018). Malachite $\left(\mathrm{Cu}_{2}(\mathrm{OH})_{2} \mathrm{CO}_{3}\right)$ is an important semi-precious mineral which has attracted extensive recent interest in various applications, for example, as coatings and catalysts

Electronic supplementary material The online version of this article (https://doi.org/10.1007/s00253-019-09961-2) contains supplementary material, which is available to authorized users.

Geoffrey Michael Gadd

g.m.gadd@ dundee.ac.uk

1 Geomicrobiology Group, School of Life Sciences, University of Dundee, Dundee DD1 5EH, Scotland, UK

2 Concrete Technology Group, Department of Civil Engineering, University of Dundee, Dundee DD1 4HN, Scotland, UK
(Gawande et al. 2016), and as an important precursor for the production of other $\mathrm{Cu}$-bearing compounds such as $\mathrm{CuO}$ as well as $\mathrm{Cu}$ (Zhang et al. 2016). Malachite, in various morphologies, has been obtained by various synthetic routes, including spherical (RodrIguez-Clemente et al. 1994), hierarchical (where the structure is different at different length scales) (Xu and Xue 2005) and nanoscale (Saikia et al. 2013). The chemical and/or physical properties of such materials vary significantly as a function of crystal size, morphology and structure, even though these materials consist of the same chemical components (Hochella et al. 2008). The development of reliable and environmentally friendly technologies for the synthesis of malachite with controlled size and structure has therefore been attracting growing interest.

Compared with traditional chemical methods, biological synthesis can be effectively employed because of cheaper starting materials and simpler processes (Thakkar et al. 2010). Biological activities can influence metal speciation, toxicity and mobility, as well as mineral formation or dissolution (Gadd and Raven 2010). Many microorganisms, 
including bacteria, yeasts and filamentous fungi, are able to produce inorganic materials in the nanoscale intracellularly or extracellularly (Gadd 2010). Through redox transformations and metabolic activities where metabolites (oxalate, carbon dioxide etc.) can be excreted, fungi are very effective in the biomineralization of metals, i.e. conversion of free metal ions into a solid insoluble biomineral form (Gadd 2007; Li et al. 2015). For example, the filamentous fungus Neurospora crassa has been successfully used for the synthesis of silver and gold nanoparticles intracellularly (Castro-Longoria et al. 2011) and cadmium carbonate nanoparticles extracellularly (Li et al. 2014). In previous studies, Neurospora crassa was found to be able to produce copper carbonate nanoparticles through the reaction of copper ions and carbonate ions which were released from urea hydrolysis by the enzyme amidohydrolase urease (Li and Gadd 2017):

$$
\begin{aligned}
& \mathrm{NH}_{2} \mathrm{CONH}_{2}+2 \mathrm{H}_{2} \mathrm{O} \rightarrow 2 \mathrm{NH}_{4}{ }^{+}+\mathrm{CO}_{3}{ }^{2-} \\
& \mathrm{H}_{2} \mathrm{O}+\mathrm{Cu}^{2+}+\mathrm{CO}_{3}{ }^{2-} \rightarrow \mathrm{CuCO}_{3}(\mathrm{OH})_{\mathrm{n}}(\mathrm{s}) \downarrow
\end{aligned}
$$

The use of filamentous fungi for nanoparticle synthesis represents a promising approach since fungi are able to secrete large amounts of chemical substances, for example, organic acids, amino acids and enzymes that may be involved in nanomaterial synthesis. The impact of such biological organic material on the biomineralization of carbonate minerals has been observed with both natural environmental samples and in laboratory studies (Braissant et al. 2003). Minerals frequently show a different ultrastructure and physico-chemical features in the presence of an organic matrix which can affect key events in mineral formation like nucleation and crystal growth stages (Briegel and Seto 2012; Jack et al. 2007; Jiang et al. 2017; Ngwenya et al. 2014). For example, Jiang et al. (2017) found that vaterite nanoparticles having a counterclockwise spiralling morphology could be induced by L-enantiomers of aspartic acid and glutamic acid, whereas a clockwise morphology was induced by D-enantiomers. However, there are very few reports on the impact of amino acids excreted by microorganisms on biomineralization of copper carbonate minerals and their potential industrial applications. The filamentous fungal growth form may also provide a template or scaffold for biomineral production that can be used to investigate the physical, chemical and biological properties of novel nanoparticles.

In this study, the influence of three amino acids (L-glutamic acid, L-aspartic acid and L-cysteine), which can be secreted by fungi, on biomineral formation was investigated. The chemical composition, morphology and thermal stability of copper carbonate synthesized by biomineralization, chemical synthesis in the presence of various amino acids, and inorganically synthesized minerals were investigated in order to characterize the mechanisms involved.

\section{Materials and methods}

\section{Organism and media}

The experimental fungus used in this study was Neurospora crassa (FGSC: 2489, Fungal Genetics Stock Centre (FGSC), Kansas, USA). It was routinely maintained on malt extract agar (MEA, Lab M limited, Bury, Lancashire, UK) in 90-mm diameter Petri dishes and grown at $25{ }^{\circ} \mathrm{C}$ in the dark. A ureamodified AP1 medium was used as the liquid media consisting of 2\% (w/v) D-glucose (Merck, Readington Township, NJ, USA), $40 \mathrm{mM}$ urea (Sigma-Aldrich, St. Louis, MO, USA), $4 \mathrm{mM} \mathrm{K} 2 \mathrm{HPO}_{4} \cdot 3 \mathrm{H}_{2} \mathrm{O}$ (Sigma-Aldrich, USA), $0.8 \mathrm{mM}$ $\mathrm{MgSO}_{4} \cdot 7 \mathrm{H}_{2} \mathrm{O}$ (Sigma-Aldrich, USA), $0.2 \mathrm{mM} \mathrm{CaCl} \cdot 6 \mathrm{H}_{2} \mathrm{O}$ (Sigma-Aldrich, USA), $1.7 \mathrm{mM} \mathrm{NaCl}$ (Sigma-Aldrich, USA), $9 \times 10^{-3} \mathrm{mM} \mathrm{FeCl}_{3} \cdot 6 \mathrm{H}_{2} \mathrm{O}$ (Sigma-Aldrich, USA) and trace metals $0.014 \mathrm{mM} \mathrm{ZnSO}_{4} \cdot 7 \mathrm{H}_{2} \mathrm{O}$ (VWR, Radnor, PA, USA), $0.018 \mathrm{mM} \mathrm{MnSO}{ }_{4} \cdot 4 \mathrm{H}_{2} \mathrm{O}$ (Sigma-Aldrich, USA) and $1.6 \times$ $10^{-3} \mathrm{mM} \mathrm{CuSO}_{4} \cdot 5 \mathrm{H}_{2} \mathrm{O}$ (VWR, USA) (Li et al. 2014). After 3 days growth in the full AP1 medium, fungal biomass was collected and washed twice in sterile MilliQ water after centrifugation $(\times 4000 \mathrm{~g}, 30 \mathrm{~min})$, and continued to be incubated in a sterile phosphate-free AP1 medium for 12 days. The initial $\mathrm{pH}$ of AP1 medium was adjusted to $\mathrm{pH} 5.5$ using $1 \mathrm{M} \mathrm{HCl}$ after autoclaving. All experiments were conducted at least in triplicate.

\section{Determination of amino acid concentrations}

One millimolar single amino acid (aspartic acid, glutamic acid, alanine, proline and cysteine, respectively) solutions and Dulbecco's modified Eagle's medium (DMEM) (SigmaAldrich, USA) were prepared separately as standards. Fifty microlitres of samples and standards was collected and analysed for the free amino acid concentration by highperformance liquid chromatography (HPLC) after derivatization. Protein was precipitated from each sample by adding $200 \mu \mathrm{l}$ trifluoroacetic acid (TFA) and methanol solution (volume ratio $=1: 10$ ) and centrifuged at $\times 20,000 \mathrm{~g}$ for $10 \mathrm{~min}$. The free amino acids were then eluted and concentrated from sample supernatants by sodium acetate, methanol, triethanolamine (TEA) solution (volume ratio $=2: 2: 1$ ), methanol, MilliQ water, TEA, phenylisothiocyanate (PITC) solution (volume ratio $=7: 1: 1: 1$ ) and methanol. Samples were dried thoroughly between each step at $46{ }^{\circ} \mathrm{C}$ in a rotary evaporator, and resuspended in eluent buffer $(95 \%$ solution of $10 \mathrm{~mL} / \mathrm{L}$ TEA and $150 \mathrm{mM}$ sodium acetate $(\mathrm{pH}=6.4)$, and 5\% acetonitrile) and separated using a Hewlett Packard 1050 HPLC system (Minneapolis, Minnesota, USA) with postcolumn UV detection (254 nm). Final results were analysed using Clarity Lite software, and all samples and standards were conducted at least in triplicate (Poncet et al. 2014). 


\section{Preparation of copper carbonate minerals}

In this study, copper carbonate minerals synthesized in the different reaction systems were compared in order to characterize the role of amino acids in biomineralization. Copper carbonate minerals were prepared (1) from biomass-free fungal growth supernatants, (2) by chemical synthesis without the addition of amino acids as a control and (3) copper precipitates obtained by chemical synthesis with the addition of glutamic acid, aspartic acid and cysteine separately at different concentrations.

\section{Copper carbonate nanoparticles produced in fungal growth supernatants}

After 12 days growth, $N$. crassa growth supernatant was collected by centrifugation $(\times 4000 \mathrm{~g}, 30 \mathrm{~min}) . \mathrm{CuCl}_{2}$ solution at a $20 \mathrm{mM}$ final concentration was added dropwise to the growth supernatant of $N$. crassa, and samples were placed on a roller shaker (60 rpm) overnight. Precipitated products were collected and washed twice with MilliQ water after centrifugation $(\times$ $10,000 \mathrm{~g}, 30 \mathrm{~min})$.

\section{Copper carbonate minerals produced by chemical synthesis}

Chemical synthesized copper carbonate minerals were used as a control and obtained by mixing $20 \mathrm{mM}$ ammonium carbonate and $20 \mathrm{mM}$ copper chloride solutions. In order to identify the impact of amino acids on copper carbonate formation, amino acids that were detected in fungal growth supernatants (glutamic acid, aspartic acid and cysteine) were also added into the chemical reaction mixture as additives to final concentrations of $0.2,1$ and $10 \mathrm{mM}$. The samples were mixed overnight on a roller shaker (60 rpm), and after collection, the minerals precipitated were examined by SEM, XRPD, FTIR and TGA to investigate the influence of amino acids on their nucleation, morphology and growth.

\section{Characterization of copper carbonate minerals}

\section{Scanning electron microscopy and energy-dispersive X-ray analysis}

Scanning electron microscopy (SEM) images were obtained by using a field emission scanning electron microscope (FESEM) (Jeol JSM7400F). Dry samples were sputter coated with $5 \mathrm{~nm}$ gold and platinum using a Cressington 208HR sputter coater (Ted Pella, Inc., Redding, CA, USA). The chemical compositions were analysed by an energydispersive X-ray spectrometer (EDXA) (Oxford Instruments, Inca, Abingdon, Oxfordshire, UK). The particle size distribution histograms of nanoparticles were calculated by measuring 150 random particles using Nano Measurer 1.2.5. software.

\section{X-ray powder diffraction analysis}

X-ray powder diffraction (XRPD) patterns were obtained with $\mathrm{Cu}-\mathrm{K} \alpha$ radiation using a Panalytical X-pert Pro diffractometer. The measurements were made using a step-scanning program with $0.02^{\circ}$ per step in the range from 0 to $100^{\circ}$. XRPD data were analysed by reference to patterns in the International Centre for Diffraction Data Powder Diffraction File (PDF) for identification of the crystalline phases.

\section{Attenuated total reflectance Fourier-transform infrared spectroscopy}

The attenuated total reflectance Fourier-transform infrared (ATR-FTIR) spectra of samples in the form of powders were obtained using a Bruker Vertex 70 FTIR spectrometer. All spectra were measured in the wavelength range from 400 to $4000 \mathrm{~cm}^{-1}$, with a $4 \mathrm{~cm}^{-1}$ spectral resolution.

\section{X-ray photoelectron spectroscopy}

X-ray photoelectron spectroscopy (XPS) was performed using a Scienta ESCA-300 instrument (Scienta AB, Uppsala, Sweden) fitted with a non-monochromatic Al-K $\alpha$ X-ray source. The survey (wide) spectra was collected from 1200 to $0 \mathrm{eV}$ with a step size of $0.2 \mathrm{eV}$, and more detailed scans for elements $\mathrm{C}, \mathrm{O}, \mathrm{N}$ and $\mathrm{Cu}$ were performed over the regions of interest. CasaXPS software was used to analyse the XPS spectra core-level lines for curve fitting. All spectra were referenced to the $\mathrm{O} 1 \mathrm{~s}$ peak of carbonate at $530.9 \mathrm{eV}$.

\section{Thermodynamic modelling by Geochemist's Workbench (GWB)}

Solubility diagrams for biomineralization and coppercomplex production in the presence of cysteine were obtained using GWB (https://www.gwb.com/index.php). The main ionic species and their activities were generated from software SpecE8, based on initial concentrations of the components in AP1 medium and solutions for coppercysteine reaction. The software Act 2 was used to construct solubility diagrams, and both SpecE8 and Act2 are included in the GWB software package. The Visual Minteq's thermodynamic database was used for this study, but modified to include the reactions of copper and cysteine (L) (Berthon 1995):

$$
\begin{array}{ll}
\mathrm{CuL}_{2} \leftrightharpoons \mathrm{Cu}^{2+}+2 \mathrm{~L}^{-} & \log \mathrm{K}=-16 \\
\mathrm{CuL} \leftrightharpoons \mathrm{Cu}^{+}+\mathrm{L}^{-} & \log \mathrm{K}=-19.19
\end{array}
$$

Log $\mathrm{K}$ is referred to stability constant of the complexes. All thermodynamic modelling was conducted at ambient temperature $\left(25^{\circ} \mathrm{C}\right)$. 


\section{Thermal properties}

Thermogravimetric analysis (TGA) was used to assess the thermal stabilities of the copper minerals produced in the presence of amino acids using a Shimadzu TGA 50 . About $50 \mathrm{mg}$ mineral samples were heated from 20 to $1000{ }^{\circ} \mathrm{C}$ at a uniform nitrogen flow rate of $100 \mathrm{ml} \mathrm{min}^{-1}$. The chemical components of the final products after thermal decomposition were analysed by XRPD.

\section{Results}

\section{Characterization of copper carbonate minerals}

$\mathrm{Cu}$-biominerals were precipitated after mixing 12-day-old Neurospora crassa growth supernatant with $20 \mathrm{mM} \mathrm{CuCl}_{2}$ solution. SEM results showed that the biominerals had a powder form, and the particles precipitated in this system were in the nanoscale with a mean diameter of $\sim 25 \mathrm{~nm}$ (Fig. 1a, b). For inorganically synthesized copper carbonate minerals from reaction of $\left(\mathrm{NH}_{4}\right)_{2} \mathrm{CO}_{3}$ and $\mathrm{CuCl}_{2}$ solutions, SEM showed various shapes and sizes of the copper carbonate minerals. After $1 \mathrm{~h}$ reaction time, the minerals produced were dispersible spherical particles with a mean diameter of $\sim 130 \mathrm{~nm}$ (Fig. 1c). After $12 \mathrm{~h}$ reaction, the mineral morphology showed highly aggregated spherical agglomerates made up of monoclinic crystals (Fig. 1d). The size of the aggregates ranged from 0.5 to $5 \mu \mathrm{m}$ in diameter.

Energy-dispersive X-ray analysis (EDXA) results showed that the main elements in the biomineral product were carbon, oxygen and copper. However, the XRPD pattern of the biominerals did not show any characteristic sharp peaks but only a broad peak which indicated the biominerals were amorphous without long-range atomic order (Fig. S1). Unlike the biominerals produced by reaction with the fungal growth supernatants, the chemical component of the inorganically synthesized copper mineral was determined as malachite $\left(\mathrm{Cu}_{2}(\mathrm{OH})_{2} \mathrm{CO}_{3}\right)$, as high-intensity peaks occurred at $15^{\circ}$, $18^{\circ}, 24^{\circ}, 31^{\circ}$ and $36^{\circ}$ corresponding respectively to the (020), (120), (220), (-201) and (240) faces of the malachite crystals (Süsse 1967).

\section{Determination of fungal extracellular amino acid secretion}

HPLC was used to determine the amino acids in the growth supernatant of $N$. crassa in phosphate-free AP1 medium. The results showed that 11 common amino acids were detected, including cysteine, alanine, glutamic acid, glycine, proline, glutamine, aspartic acid, valine, phenylalanine and arginine. In order to identify the amino acids potentially involved in the biomineralization of copper carbonate nanoparticles, the concentration of amino acids remaining in the supernatant after biomineralization was also measured by HPLC. The concentration of all the amino acids decreased after mineral formation which suggested the removal of amino acids from solution through association with the copper carbonate minerals (Fig. 2). For some of the amino acids detected, for example, valine, alanine and aspartic acid, more than $80 \%$ of the original amounts were removed after bioprecipitation which indicated a high affinity to bind to the biominerals (Table S1).

\section{Effect of amino acids on the formation of copper carbonate minerals}

Mineral morphology The impact of the 11 amino acids that were produced by $N$. crassa on the particle morphology of the copper carbonate was investigated in preliminary studies. Among the amino acids, glutamic acid was found to prevent particle aggregation and produce nanoparticles at a $1 \mathrm{mM}$ concentration. Samples with different concentrations $(0.2,1$ and $10 \mathrm{mM}$ ) of phenylalanine, arginine, valine and proline did not show much effect on nanoparticle morphology or structure. When the amino acid concentration was increased to $10 \mathrm{mM}$, some nanoparticles were produced in the presence of glutamine, alanine, serine, glycine and glutamic acid of size around 100-200 nm in diameter. We selected L-glutamic acid, Laspartic acid and L-cysteine as target amino acids for more detailed study due to the formation of nanoparticles and unique 'fibrous' minerals in the presence of these amino acids (Fig. S2, Fig. S3). SEM revealed that when copper carbonate was synthesized in the presence of $0.2 \mathrm{mM}$ amino acids, all the samples were spherical and formed irregularly shaped aggregates with particle size distribution ranging from $\sim 0.3$ to $3 \mu \mathrm{m}$ in diameter (Fig. 3a, d, g). Aggregates growing in clusters were also observed. Each individual aggregate comprised an assemblage of many superfine particles with sizes under $100 \mathrm{~nm}$. These nanoscale particles were uniform, and were tightly compacted for most of the samples, although some samples exhibited a degree of porosity, e.g. the minerals produced with $0.2 \mathrm{mM}$ cysteine (Fig. 3g). With increasing concentration of amino acids, various shapes and sizes of minerals were produced. The images revealed that the particles produced in the presence of $1 \mathrm{mM}$ glutamic acid were polydispersed and ranged from $\sim 100$ to $200 \mathrm{~nm}$ in diameter (Fig. 3b, Fig. S4). Unlike the spherical particle aggregates, some fibrous rod-like structures were observed in the samples with increasing concentrations of cysteine and aspartic acid (Fig. 3f, i). It was also observed that the groups of fibres showed a similar orientation, with the length usually ranging from $\sim 2$ to $3 \mu \mathrm{m}$.

XRPD analysis The XRPD pattern of copper carbonate particles synthesized inorganically confirmed them to be malachite $\left(\mathrm{Cu}_{2}(\mathrm{OH})_{2} \mathrm{CO}_{3}\right)$. When the concentration of added amino acid 

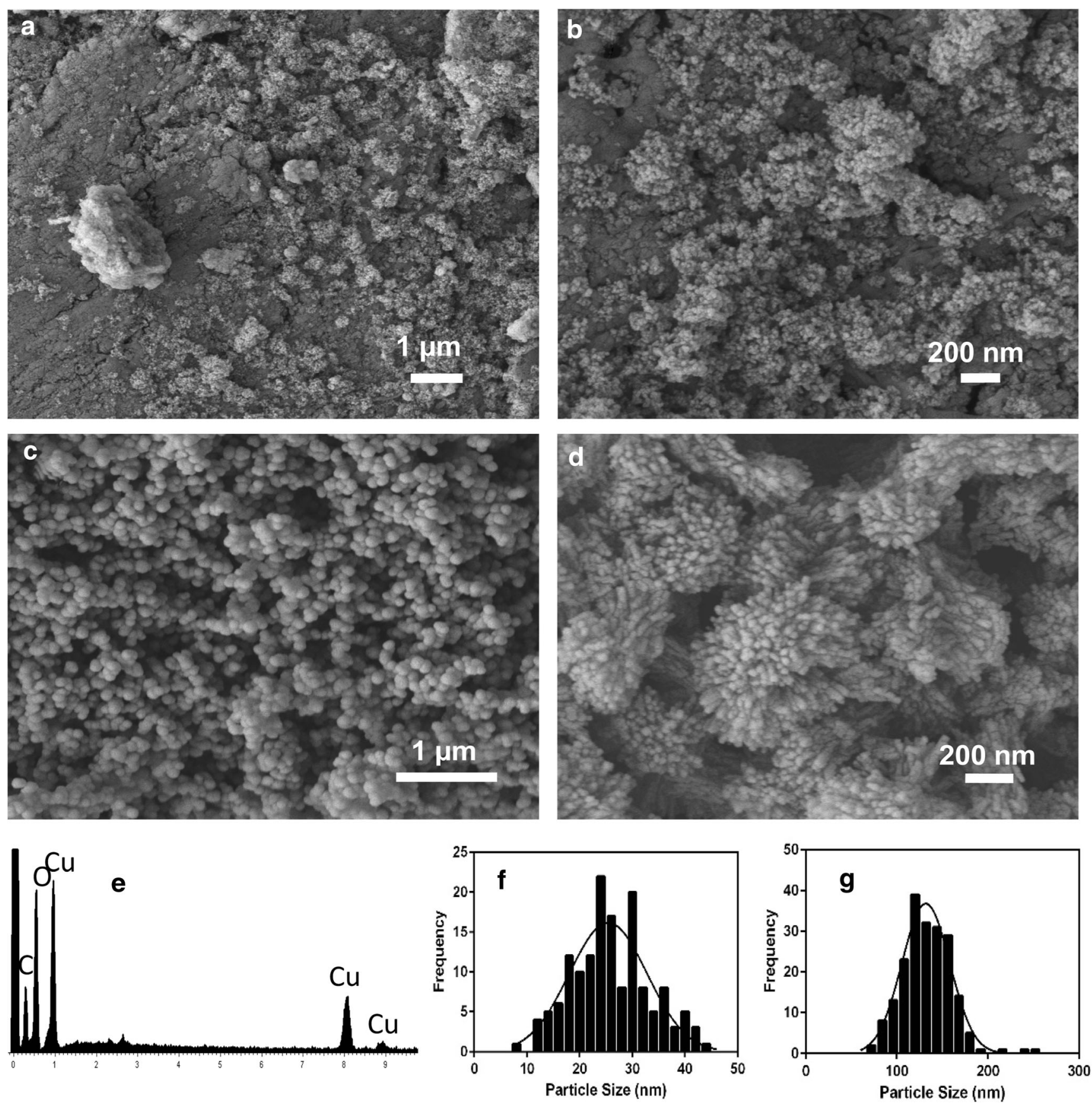

Fig. 1 SEM images of copper carbonate minerals synthesized by $\mathbf{a}, \mathbf{b}$ mixing 12-day-old Neurospora crassa growth supernatant with $20 \mathrm{mM}$ $\mathrm{CuCl}_{2}$ after incubation for $16 \mathrm{~h}$, and $\mathbf{c}, \mathbf{d}$ mixing of $20 \mathrm{mM}\left(\mathrm{NH}_{4}\right)_{2} \mathrm{CO}_{3}$ and $20 \mathrm{mM} \mathrm{CuCl}_{2}$. e EDXA data of the main elements in the sample

was low $(0.2 \mathrm{mM})$, the chemical composition of the minerals produced in the presence of the amino acid was also determined as malachite (Fig. 4). There were some broad peaks in the XRPD patterns of the samples with $1 \mathrm{mM}$ and $10 \mathrm{mM}$ glutamic acid, which indicated that minerals with a very small size had been produced, based on the Scherrer equation (Patterson 1939). For the samples with $10 \mathrm{mM}$ cysteine and $10 \mathrm{mM}$ aspartic acid, characteristic peaks for malachite, and other inorganic copper- synthesized from fungal growth supernatant. f, g Size distribution histograms of particles produced from fungal growth supernatant and mixing of $20 \mathrm{mM}\left(\mathrm{NH}_{4}\right)_{2} \mathrm{CO}_{3}$ and $20 \mathrm{mM} \mathrm{CuCl}_{2}$ after $1 \mathrm{~h}$ of reaction. Typical images and spectrum are shown from several determinations

bearing minerals were not detected. Some very finely crystallized minerals were formed, and minerals with a unique fibrous structure were observed for these two samples. Some promising results were obtained from the XRPD database, as patterns for $\mathrm{C}_{20} \mathrm{H}_{18} \mathrm{CuN}_{4} \mathrm{O}_{6}(00-705-2616)$ and $\mathrm{C}_{33} \mathrm{H}_{30} \mathrm{Cu}_{3} \mathrm{O}_{21} 2 \mathrm{CH}_{3} \mathrm{OH}$ (00-151-4153) were very similar to the XRPD patterns of the samples with cysteine and aspartic acid, therefore suggesting the formation of complexes between copper and the amino acids. 
Fig. 2 Concentrations of eleven amino acids detected in $N$. crassa culture supernatant after 12-days incubation and in the supernatant after biomineralization and removal of resultant copper carbonate precipitated. The image inset shows the concentrations of amino acids without cysteine. Analyses were conducted at least in triplicate, and the bars shown are one standard error of the mean

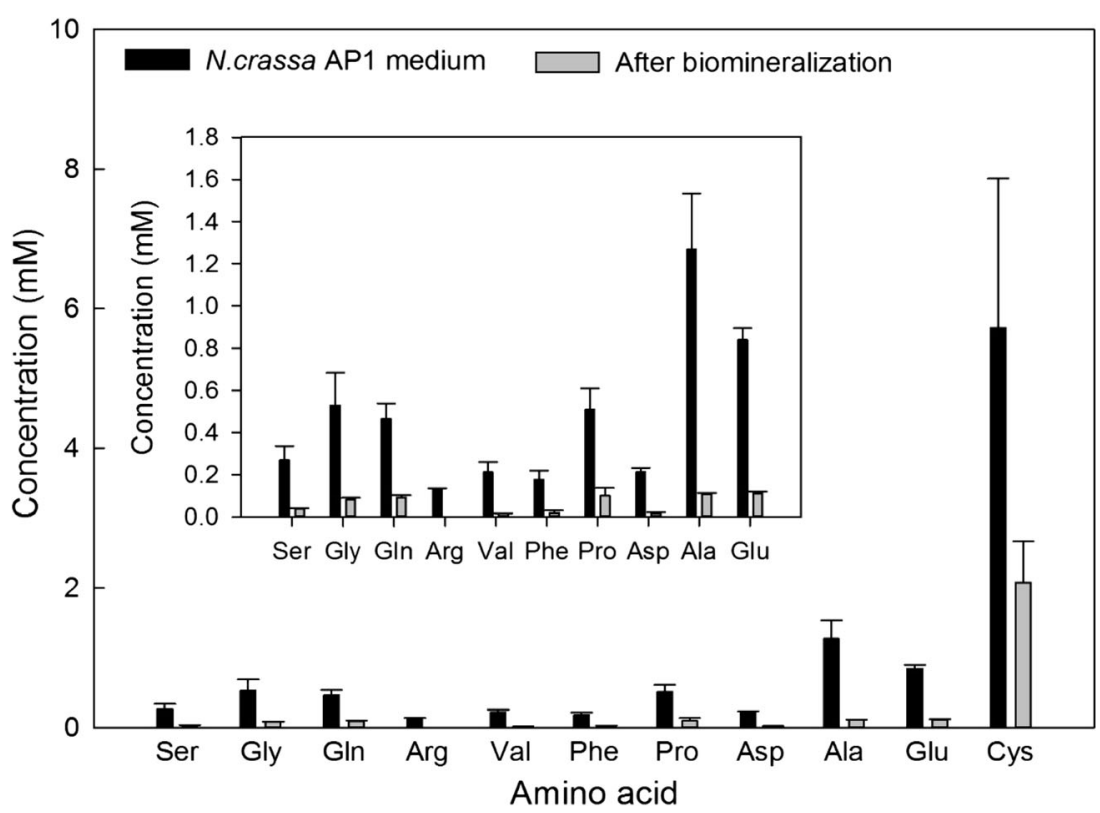

FTIR spectral analysis ART-FTIR was conducted to identify possible interactions between the copper minerals and organic additives, as amino acids could be incorporated into the mineral structure during crystal growth. FTIR spectra can also provide additional identification for the amorphous minerals which showed no discernible patterns in XRPD analysis. A broad band was observed at around $3400 \mathrm{~cm}^{-1}$ which represented the stretching vibration of intermolecular bonded $\mathrm{OH}$ groups (Fig. 5). Based on previous studies, some characteristic peaks of the $\mathrm{CO}_{3}{ }^{2-}$ group at 1497 and 1380 (asymmetric stretch), 1043 (symmetric stretch) and $869 \mathrm{~cm}^{-1}$ (bending mode) were present in the spectrum of the inorganic control which again confirmed the formation of copper carbonate (Liu et al. 2016). For the samples produced from the fungal growth supernatant and those produced in the presence of glutamic acid, which showed amorphous patterns in XRPD analysis, FTIR patterns became broader and less sharp as atomic disorder increased. FTIR patterns of biominerals and mineral produced in the presence of $10 \mathrm{mM}$ glutamic acid were very similar with malachite, with characteristic peaks of $\mathrm{CO}_{3}{ }^{2-}$ group at 1497 and $1380 \mathrm{~cm}^{-1}$, suggesting the formation of carbonate minerals. The peak at $1497 \mathrm{~cm}^{-1}$ shifted towards a higher wavelength in all biomineral and amino acid samples. At this region, the bending of N-H $\left(\sim 1600 \mathrm{~cm}^{-1}\right)$ of amines and the stretching vibration of the $\mathrm{CO}_{3}{ }^{2-}$ group $\left(1497 \mathrm{~cm}^{-1}\right)$ overlapped. This might be attributable to hydrogen bonding between the carboxyl groups of amino acids and the oxygen of the carbonyl groups, indicating the molecular interaction between amino acids and carbonate minerals (Ghadiri et al. 2014). In addition, for the biomineral sample, peaks in the 2920 to $2853 \mathrm{~cm}^{-1}$ region represent the asymmetric and symmetric stretching vibration of the $\mathrm{C}-\mathrm{H}$ of alkanes, respectively, which is evidence for the association of organic materials secreted by the fungus into the mineral structure (Xu et al. 2012). For the samples with aspartic acid and cysteine, very strong N-H bending peaks $\left(\sim 1622 \mathrm{~cm}^{-1}\right)$ can be determined, as well as some other organic peaks belonging to amino acids (Table 1). The characteristic carbonate peaks were absent in the spectrum of the sample produced in $10 \mathrm{mM}$ cysteine. Significantly, cysteine usually shows a strong peak near $2540 \mathrm{~cm}^{-1}$, which confirms the presence of thiol groups ($\mathrm{SH}$ ) in the cysteine molecule (Pawlukojć et al. 2005). This peak disappeared in the spectrum of the sample produced in the presence of $10 \mathrm{mM}$ cysteine, suggesting the thiol group of cysteine was associated within minerals through the formation of $\mathrm{Cu}-\mathrm{S}$ bonds. These results indicate the formation of $\mathrm{Cu}-$ aspartate and $\mathrm{Cu}$-cysteine complexes.

X-ray photoelectron spectroscopy X-ray photoelectron spectroscopy (XPS) was performed to study the surface chemical properties of $\mathrm{Cu}$ carbonate precipitates derived from the fungal growth supernatant. XPS spectra over a binding energy range of $1200-0 \mathrm{eV}$ (Fig. 6a) showed the presence of C, N, $\mathrm{O}$ and $\mathrm{Cu}$ on the biomineral samples. The presence of $\mathrm{N}$ was attributed to organic components that bound to the mineral surface, for example, secreted amino acids and proteins. The valence states of the biominerals were further characterized by high-resolution XPS spectra as shown in Fig. 6b-e. Some 'shake-up' satellite peaks at binding energies of 940 945 eV shown in the high-resolution $\mathrm{Cu} 2 \mathrm{p} 3 / 2$ spectrum are characteristic features of $\mathrm{Cu}(\mathrm{II})$, which indicates the presence of various $\mathrm{Cu}$ (II) species based on the complexity of the shake-up structures (Fig. 6b). $\mathrm{Cu} 2 \mathrm{p}$ main peaks could be fitted into two components at $934.6 \mathrm{eV}$ and $932.7 \mathrm{eV}$, which are assigned to 

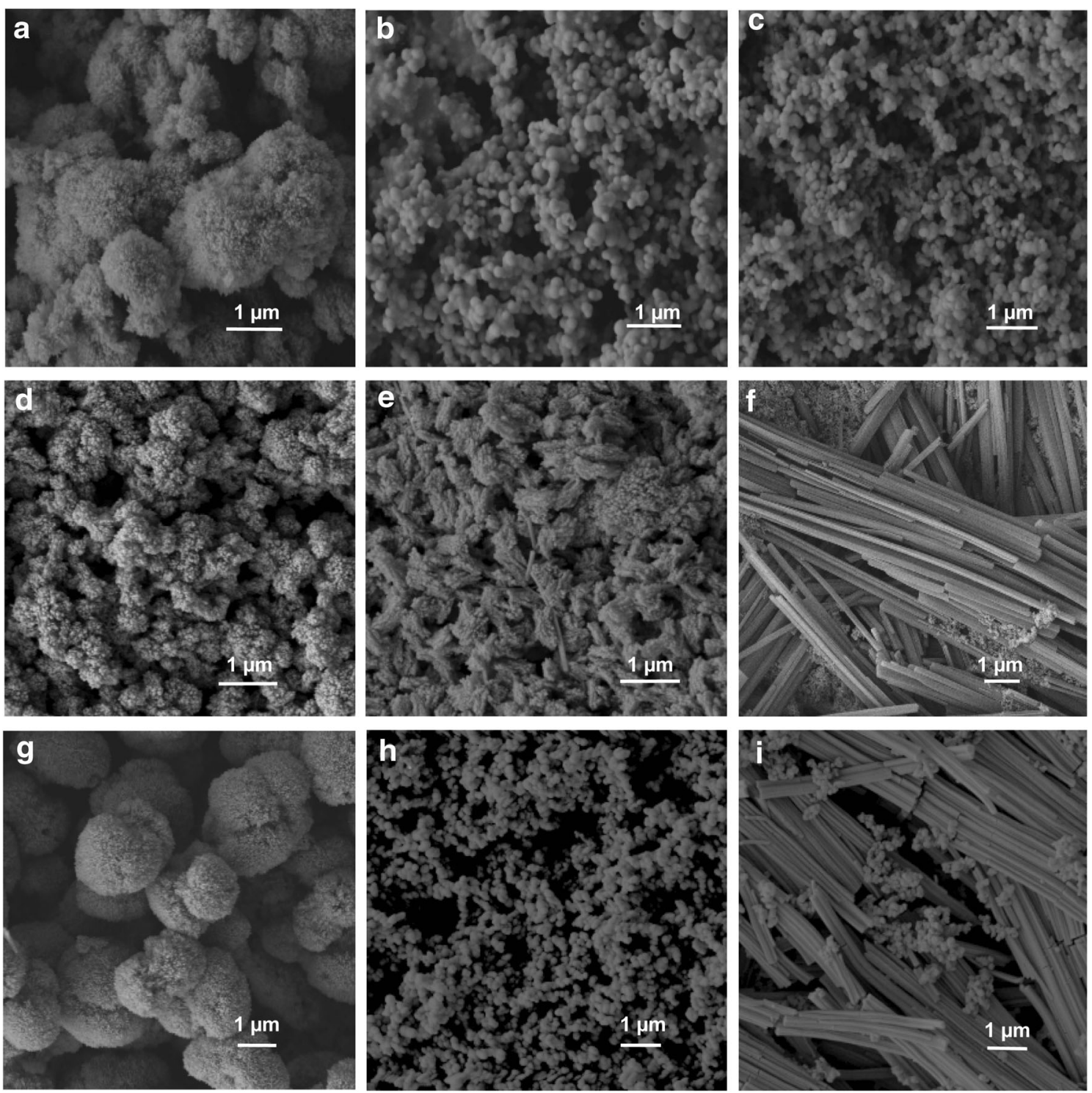

Fig. 3 SEM images of copper carbonate nanoparticles formed with/without the addition of various amino acids. a-c $0.2,1$ and $10 \mathrm{mM}$ L-glutamic acid. d-f $0.2,1$ and $10 \mathrm{mM}$ L-aspartic acid. $\mathbf{g}-\mathbf{i}$ 0.2, 1 and

$10 \mathrm{mM}$ L-cysteine, respectively. The scale bars are $1 \mu \mathrm{m}$, and typical images are shown from several separate determinations

$\mathrm{Cu}(\mathrm{II})$ and $\mathrm{Cu}(\mathrm{I}) / \mathrm{Cu}(0)$, separately (Biesinger 2017). Both metal carbonates and organic $\mathrm{C}-\mathrm{O}$ bonds give a $\mathrm{O} 1 \mathrm{~s}$ contribution at the approximate same binding energy (Stoch and Gablankowska-Kukucz 1991), and the complexity of various $\mathrm{Cu}$ (II)-containing minerals (e.g. $\mathrm{Cu}_{2} \mathrm{CO}_{3}(\mathrm{OH})_{2}, \mathrm{Cu}(\mathrm{OH})_{2}, \mathrm{Cu}$ complexes) makes assignment of the $\mathrm{O} 1 \mathrm{~s}$ region more complex (Fig. 6c). These factors could account for the downward shift of the O1s peak $(\sim 531 \mathrm{eV})$ compared with the O1s peak detected for standard malachite $(531.5 \mathrm{eV})$ (Wagner et al. 1980). The C1s spectrum could be deconvoluted into two individual peaks with binding energies of 284.6 and $287.6 \mathrm{eV}$ (Fig. 6d). The peak at 284.6 can be assigned to non-oxygenated C-C or C-H bonding (Choi et al. 2009). The peak at $287.6 \mathrm{eV}$ could be the carbonate peak shifting to a lower binding energy, which can be attributed to the interaction of carbonate with lower positive oxidation state bonding, for example, amine C-N bonding (286 eV) (Tawil et al. 2013) or possibly the formation of bicarbonate $\mathrm{HCO}_{3}{ }^{-}$. The N1s peak could not be fitted with a single symmetrical component. Besides the $\mathrm{C}-\mathrm{NH}_{2}$ bond at $399.5 \mathrm{eV}$, a lowintensity component at a binding energy of $397.2 \mathrm{eV}$ was also found in the spectrum (Fig. 6e), which is believed to be $\mathrm{Cu}-\mathrm{N}$ bonding (Meng et al. 2017). The formation of $\mathrm{Cu}-\mathrm{N}$ could be an indicator of the reaction of organics with $\mathrm{Cu}$, leading to the association of $\mathrm{N}$ on the surface of the biominerals.

Speciation modelling using Geochemist's Workbench The stability of copper minerals was assessed using Geochemist's Workbench (GWB) by modelling the predominance of chemical species in the fungal growth supernatant in order to 

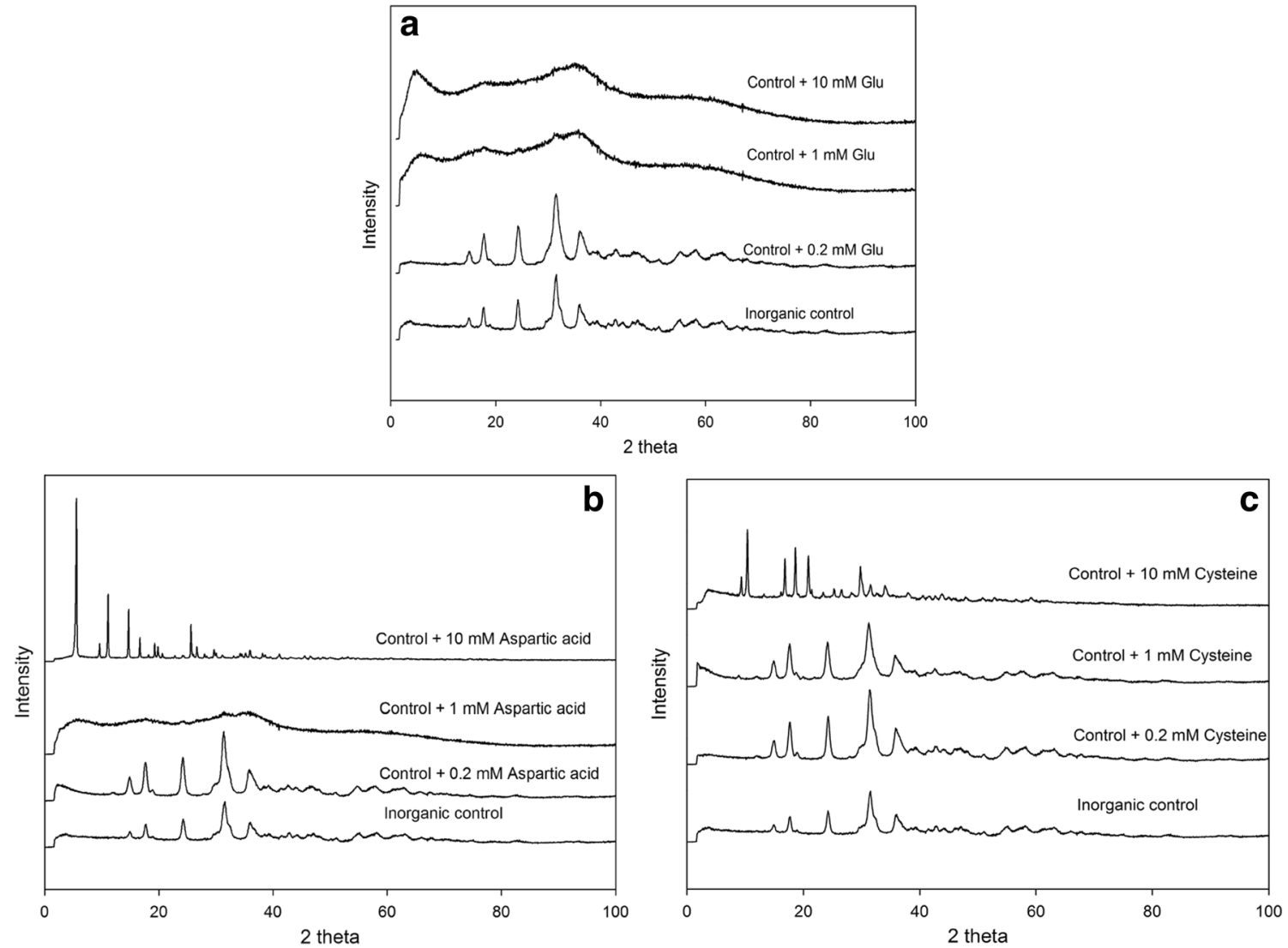

Fig. 4 XRPD patterns of copper nanoparticles formed with/without the addition of various amino acids (a, L-glutamic acid; b, L-aspartic acid; c, Lcysteine) to concentrations of $0.2,1$ and $10 \mathrm{mM}$, respectively. Typical patterns are shown from several separate determinations

determine the chemical components of the biomineralization products. The $\mathrm{pH}$ of $N$. crassa growth supernatant was around pH 8.5 after 12-day incubation. Based on the solubility diagram, when the concentration of $\mathrm{Cu}^{2+}$ was $20 \mathrm{mM}$, the only possible mineral precipitated in this system was malachite (Fig. 7). The modelling results for the reaction of copper
Fig. 5 FTIR transmittance spectra of synthesized inorganic malachite (control), copper carbonate minerals precipitated from $N$. crassa growth supernatant (biominerals) and copper minerals produced in the presence of $10 \mathrm{mM}$ L-glutamic acid, L-aspartic acid and Lcysteine. A typical spectrum is shown

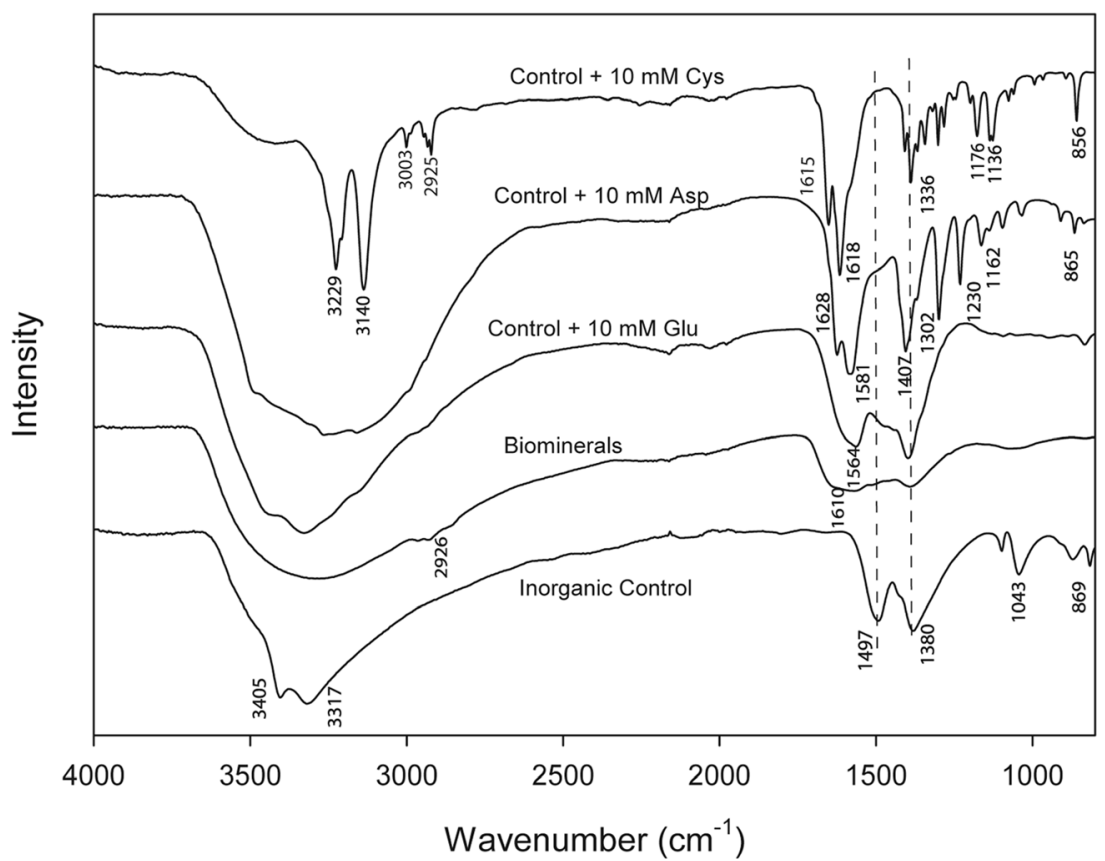


Table 1 FTIR data of copper complexes produced in the presence of $10 \mathrm{mM}$ aspartic acid (Cu-asp) and $10 \mathrm{mM}$ cysteine (Cu-cys), respectively

\begin{tabular}{llll}
\hline $\begin{array}{l}\text { Cu-asp complexes } \\
\text { Wavelength }\left(\mathrm{cm}^{-1}\right)\end{array}$ & $\begin{array}{l}\text { Assignments } \\
(\text { Navarrete et al. 1994) }\end{array}$ & $\begin{array}{l}\text { Cu-cys complexes } \\
\text { Wavelength }\left(\mathrm{cm}^{-1}\right)\end{array}$ & $\begin{array}{l}\text { Assignments } \\
\text { (Pawlukojć et al. 2005) }\end{array}$ \\
\hline 865 & $\mathrm{CC}_{\text {str. }}$ & 856 & $\mathrm{CC}_{\text {str. }}$ \\
910 & $\mathrm{CH}_{2 \text { rock. }}$ & 1076 & $\mathrm{NH}_{3 \text { rock. }}$ \\
1097 & $\mathrm{CN}_{\text {str. }}$ & 1136 & $\mathrm{CH}_{\text {bend. }}$ \\
1162 & $\mathrm{NH}_{3 \text { rock. }}$ & 1176 & $\mathrm{CH}_{2 \text { twist. }}$ \\
1230 & $\mathrm{CH}_{2 \text { twist. }}$ & 1302 & $\mathrm{CH}_{2 \text { wagg. }}$ \\
1302 & $\mathrm{NH}_{3 \text { rock, }}$ & 1388 & $\mathrm{CO}_{2 \text { sym. }}$ \\
1407 & $\mathrm{CO}_{\text {str. }}$ & 1579 & $\mathrm{NH}_{3 \text { bend. }}$ \\
1584 & $\mathrm{CO}_{2 \text { str. }}$ & 1618 & $\mathrm{NH}_{3 \text { bend. }}$ \\
1628 & $\mathrm{NH}_{3 \text { bend. }}$ & 1651 & $\mathrm{CO}_{2 \text { str. }}$ \\
& & 2925 & $\mathrm{CH}_{\text {str. }}$ \\
& & 3003 & $\mathrm{CH}_{2 \text { str. }}$ \\
& & 3140 & $\mathrm{NH}_{3 \text { str. }}$ \\
& & 3229 & $\mathrm{NH}_{3 \text { str. }}$ \\
\hline
\end{tabular}

and cysteine showed the formation of $\mathrm{Cu}$-cysteine complexes at $\mathrm{pH}=8.5$. Compared with the $N$. crassa growth supernatant, it was therefore not possible for malachite $\left(\mathrm{Cu}_{2}(\mathrm{OH})_{2} \mathrm{CO}_{3}\right)$ to be precipitated in the presence of cysteine.

Thermal stability analysis The association of amino acids, and other organic materials produced by the fungus, with the minerals was also confirmed by thermogravimetric analysis (TGA). Representative derivative thermogravimetric analysis (DTA) and TGA profiles are shown in Fig. 8. The samples containing organic matter, including the minerals produced by biomineralization and those precipitated in the presence of amino acids, showed more weight loss compared with the inorganically synthesized minerals. Organic material is
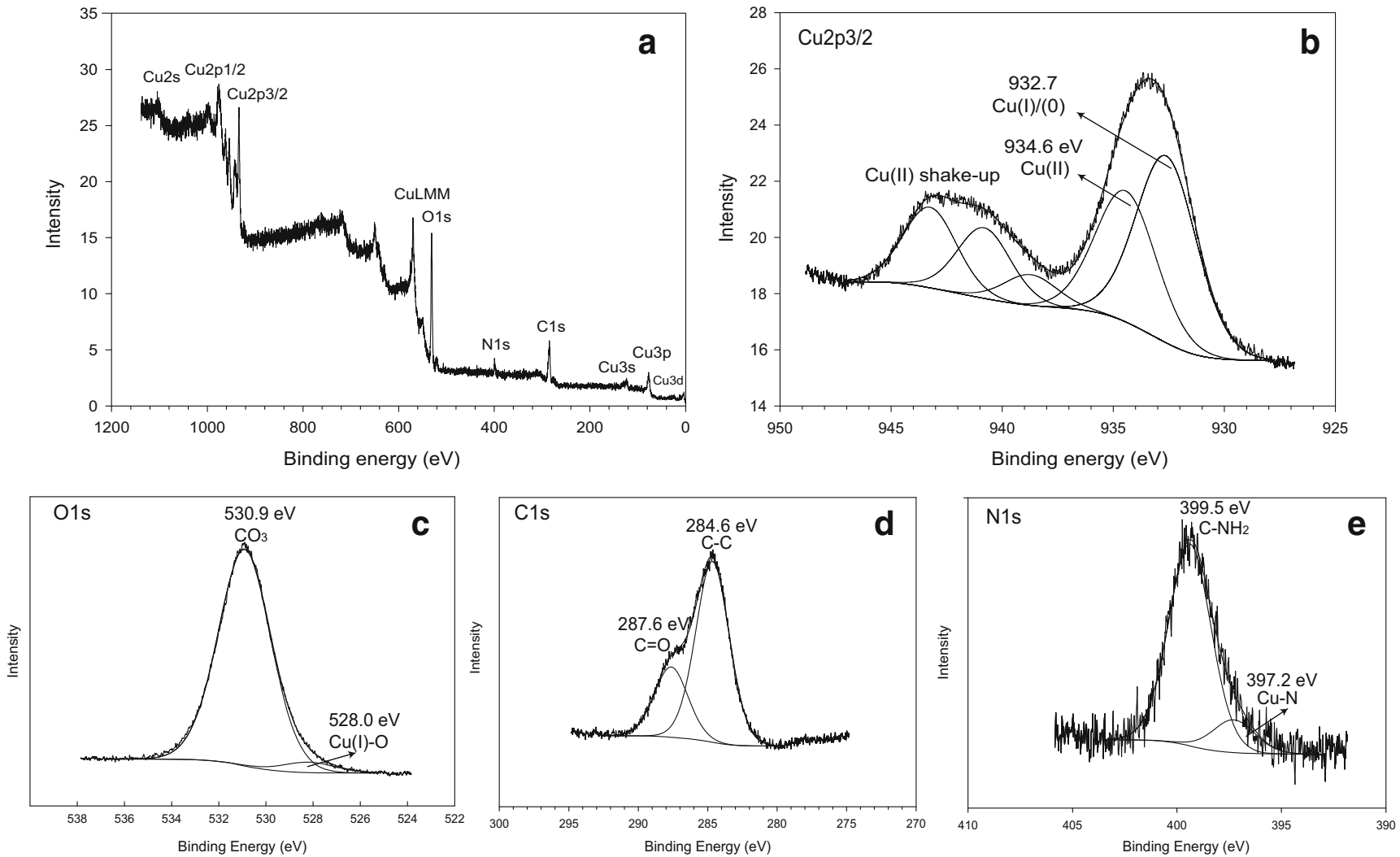

Fig. 6 XPS spectra of copper carbonate minerals precipitated from $N$. crassa growth supernatant. a Total spectra and b-e XPS Cu2p, O1s, C1s and N1s spectra. A Typical spectra are shown 
Fig. 7 Solubility diagrams of $\mathrm{Cu}^{2+}$ versus $\mathrm{pH}$ at $25^{\circ} \mathrm{C}$ for (left) biomineralization in a simulated AP1 fungal growth supernatant and (right) the reaction of inorganic $\left(\mathrm{NH}_{4}\right)_{2} \mathrm{CO}_{3}$ and $\mathrm{CuCl}_{2}$ in the presence of $20 \mathrm{mM}$ cysteine

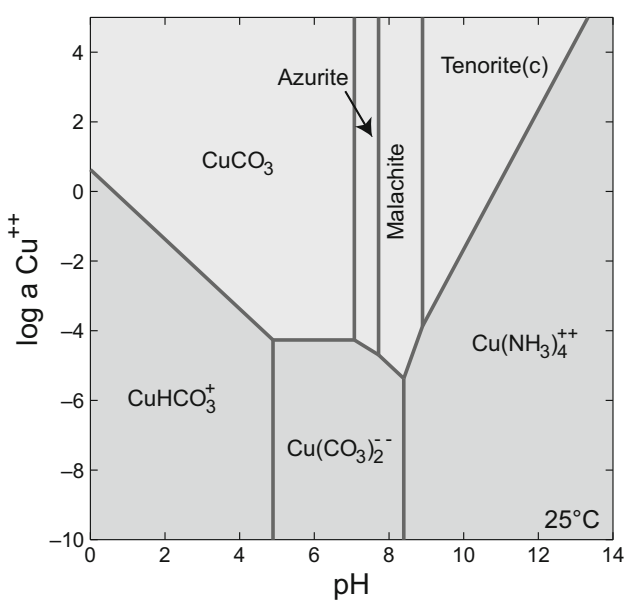

decomposed at $600{ }^{\circ} \mathrm{C}$, and the percentage weight loss between 75 and $600{ }^{\circ} \mathrm{C}$ of the control sample, biomineral and samples obtained in the presence of $10 \mathrm{mM} \mathrm{Glu}$, Asp and Cys was $30.2 \%, 48.3 \%, 52.8 \%, 55.6 \%$ and $45.9 \%$, respectively. This calculation allows for an initial mass loss due to the loss of physically adsorbed water from 60 to $75^{\circ} \mathrm{C}$. The decomposition of organic materials which were associated with the minerals, i.e. amino acids, contributed to the additional weight loss compared with the control sample. Specifically, it can be seen that the sample with $10 \mathrm{mM}$ aspartic acid showed the highest weight loss, which was $22.3 \%$ greater than the inorganic control samples. In spite of losing physically adsorbed water, control abiotically synthesized malachite showed three decomposition peaks, at 169,264 and $952^{\circ} \mathrm{C}$, which can be attributed to the loss of $\mathrm{OH}$, decomposition of copper carbonate and the loss of the oxygen of copper oxide in an inert atmosphere, respectively (Ding et al. 2002; Frost et al. 2002). The peaks around $100-200{ }^{\circ} \mathrm{C}$ were related to the decomposition of amino acids. For the samples with glutamic acid/biominerals, the peaks present at the temperature around 250-300 ${ }^{\circ} \mathrm{C}$ can represent decomposition of the amino acids which were intercalated between the molecular structures of the minerals. Amino acids can be decomposed easily at temperatures around $200{ }^{\circ} \mathrm{C}$ (Rodante and Marrosu 1990). Intercalated amino acids inside mineral structures can be protected against decomposition therefore showing a relatively higher decomposition temperature. The peaks of copper carbonate decomposition (around $264{ }^{\circ} \mathrm{C}$ ) shifted towards a lower temperature in the glutamic acid/biomineral samples which indicated that the decomposition of amino acids leads to an obvious decrease in the thermal stability of the malachite. For the sample with $10 \mathrm{mM}$ glutamic acid, the temperature for loss of oxygen decreased from 947 to $419{ }^{\circ} \mathrm{C}$. For the samples produced in the presence of aspartic acid and cysteine, two strong signals were observed around 190 to $230{ }^{\circ} \mathrm{C}$, suggesting the decomposition of $\mathrm{Cu}$-amino acid complexes.

XRPD analysis of the final products after thermal decomposition (Fig. S5) showed that different copper-bearing minerals resulted. For the inorganic control, cuprite $\left(\mathrm{Cu}_{2} \mathrm{O}\right)$ was produced. The biominerals, the sample with $10 \mathrm{mM}$ glutamic acid and $10 \mathrm{mM}$ aspartic acid showed the production of metallic copper after TG analysis. It is therefore suggested that the copper carbonate minerals containing organic material were more easily reduced to metallic copper compared to the inorganic controls, and they may also possess less thermal
Fig. 8 a Differential thermal analysis (DTA) of synthesized inorganic malachite (control), copper carbonate minerals precipitated from $N$. crassa growth supernatant (biominerals) and copper minerals produced in the presence of $10 \mathrm{mM} \mathrm{L-}$ glutamic acid, L-aspartic acid and L-cysteine; b shows the thermogravimetric analysis (TGA) of the same samples
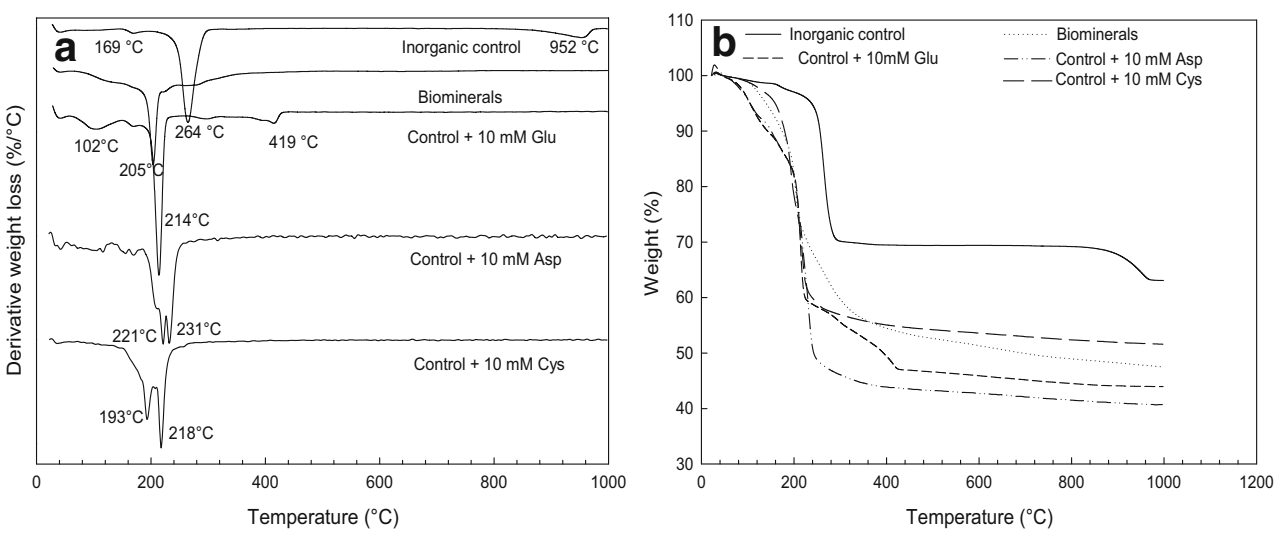
stability. TGA of the samples produced with $10 \mathrm{mM}$ cysteine gave pure phase chalcocite $\left(\mathrm{Cu}_{2} \mathrm{~S}\right)$.

\section{Discussion}

The copper carbonate nanoparticles formed by a fungalmediated biomineralization reaction showed an amorphous powder form without any clear crystallinity, and this result was also consistent with XRPD data as no distinguishable peaks in XRPD patterns were observed for the amorphous minerals in the absence of any ordered atomic structure. Although the GWB modelling and FTIR results suggested that basic copper carbonate, malachite $\left(\mathrm{Cu}_{2}(\mathrm{OH})_{2} \mathrm{CO}_{3}\right)$, was formed under the experimental conditions, the presence of amino acids and other organic molecules secreted from fungi can affect the purity and valence state of the $\mathrm{Cu}$ mineral. The $\mathrm{Cu} 2 \mathrm{p} 3 / 2$ XPS bands appeared at around $932 \mathrm{eV}$ which was assigned to either $\mathrm{Cu}(\mathrm{I})$ or $\mathrm{Cu}(0)$ species, indicating the reductive $\mathrm{Cu}$ species formed via some complex-forming reactions inside the structure of the copper carbonate minerals. Our XPS results further suggested the $\mathrm{Cu}$ complexes were formed by bonding the $\mathrm{N}$ atoms of organic molecules with the $\mathrm{Cu}$ species $(\mathrm{Cu}-\mathrm{N})$ on the mineral surface. Liu et al. (2016) studied the reaction of a novel organic surfactant HATT (which has amino and thione functional groups) with malachite, and showed that HATT was associated with malachite by the formation of $\mathrm{Cu}-$ $\mathrm{N}$ and $\mathrm{Cu}-\mathrm{S}$ surface complexes. It is not unusual that $\mathrm{Cu}(\mathrm{II})$ can be reduced to $\mathrm{Cu}$ (I) and form $\mathrm{Cu}$ (I) and/or $\mathrm{Cu}$ (II) complexes with amino acids, e.g. glycine (Cedzynska et al. 1981) and cysteine (Rigo et al. 2004). Redox reactions of $\mathrm{Cu}$ are also involved in many enzymatic processes, for example the functions of copper chaperone and copper transport proteins (Valentine and Gralla 2002). Some previous studies showed that cysteine and tyrosine residues played a key role in the reduction of $\mathrm{Cu}(\mathrm{II})$ to $\mathrm{Cu}(\mathrm{I})$ by some copper-binding proteins (Opazo et al. 2003).

Nanoparticles produced from the biomineralization reaction showed the smallest particle size (mean diameter around $26 \mathrm{~nm}$ ), compared to the inorganically synthesized sample and samples obtained in the presence of various amino acids. Nucleation and growth of nanoparticles is closely associated with the microenvironment of the specific particle system (Thanh et al. 2014). The reaction conditions, concentration of solute and particle surface charge, as well as the presence of organic matter can have an important influence on the final morphology of such particles. Since the fungal growth supernatant contained various metabolites, including free amino acids, proteins and extracellular polymeric substances (EPS), which can act as stabilizing agents in nanoparticle formation (Tourney and Ngwenya 2014), such biomolecules may be bound and subsequently block growth sites on the surface of copper carbonate particles after 'burst-nucleation'. The mean particle size $(D)$ is related to both the particle growth rate and the nucleation rate:

$D=1.203(G / N)^{1 / 3}$

where $G$ refers to the particle growth rate and $N$ is the nucleation rate (Byrne et al. 2011). When the growth rate of nuclei is inhibited, the resultant particle size is smaller, and this explains the deficient development of crystal structure and the formation of amorphous, nanoscale particles.

The copper carbonate precipitated in the presence of various concentrations of different amino acids showed different morphologies compared with abiotically synthesized copper carbonate particles produced from mixture of $20 \mathrm{mM}$ $\left(\mathrm{NH}_{4}\right)_{2} \mathrm{CO}_{3}$ and $20 \mathrm{mM} \mathrm{CuCl}_{2}$. The mean size of the inorganic control copper carbonate particles in the absence of any additives was $\sim 130 \mathrm{~nm}$ in diameter after $1 \mathrm{~h}$ reaction time, and these crystals aggregated together to form microscale particles after $12 \mathrm{~h}$. Nanoparticles have a high surface area to volume ratio, and the total free energy of nanoparticles tends to decrease on reducing the interfacial area to maintain the stability of the system. This usually results in particle agglomeration or recrystallization. One of the most remarkable features of these minerals was the uniformity of the nanocrystals within the aggregates which all had the same morphology and size, and this suggested that the nanoparticles nucleated simultaneously and grew at the same rate before aggregation (Kwon and Hyeon 2008). When various amino acids were added into the chemical reaction of copper carbonate, the incorporation of amino acids within the mineral structure was confirmed by FTIR analysis. Among all the amino acids tested, the reaction with $10 \mathrm{mM}$ glutamic acid produced the smallest sized particles, and these particles were stabilized in the early phase of crystal growth and prevented from aggregation with only $1 \mathrm{mM}$ glutamic acid. It is reported that the point of zero charge (pzc) of malachite is around $\mathrm{pH}$ 7.6, and malachite also has a high positive charge, $\sim 20 \mathrm{mV}$ on the surface at a neutral $\mathrm{pH}$ (Saha and Das 2009). Therefore, it can be concluded that the negatively charged amine group side chain of glutamic acid showed a high affinity for binding to positive mineral surfaces (Wang et al. 2015; Wolthers et al. 2008; Zare et al. 2013). Whether particles stay dispersed or aggregated in a system is controlled by repulsive and attractive forces between particles, for example, gravity, electrical charge and van der Waals forces (Adamczyk and Weroński 1999). It is therefore suggested that the Gluassociated particles with a negatively charged surface would have a stronger repulsive force than an attractive force which would make the particles more dispersible and also inhibit their further growth. The mean size of particles synthesized in the presence of $10 \mathrm{mM}$ Glu was $\sim 130 \mathrm{~nm}$ in diameter, which was smaller than those produced in the presence of $1 \mathrm{mM}$ Glu (mean diameter $\sim 160 \mathrm{~nm}$ ). It is suggested an increasing concentration of the added amino acid can decrease the activation 
energy for nucleation, increase the rate of nucleation and decrease the size of the crystals (Mann 2001).

For acidic amino acids like aspartic acid, it was found that these amino acids resulted in the formation of rod-like crystals. Long fibrous crystals were also observed in the samples with $10 \mathrm{mM}$ cysteine. Peptides and amino acids can interact with divalent transition metals, and form 'complexes' that have received significant attention, especially the copper complexes of amino acids (Kryukova et al. 2005). The synthesis of such complexes via complexation and chelation also highlights the possibility of artificial mimics of metal-containing enzymes for use as catalysts. Previous work reported using the copper-cysteine complexes to enhance photocatalytic $\mathrm{H}_{2}$ production by 150 times compared with CdSe catalyst (Peng et al. 2015). In our reaction system, as shown by the GWB modelling results, the amino and carboxylate groups of aspartic acid and cysteine can chelate copper ions preferentially compared with carbonate ions, which will further prevent the formation of copper carbonate minerals (Sóvágó et al. 2012). The oriented nucleation and growth of minerals, which enhanced growth in specific directions but limited growth rates in other directions, resulted in formation of minerals with rod-like or fibrous structure. The formation of $\mathrm{Cu}_{2} \mathrm{~S}$ from thermolysis of $\mathrm{Cu}$-cysteine complexes confirmed the breakup of thiol group and formation of $\mathrm{Cu}-\mathrm{S}$ bonding, which can shed some light on the production of copper sulphide with impressive electrocatalytic properties (Choi et al. 2009).

Biominerals that exist in natural and synthetic environments show a variety of morphologies and structures, but the effect of small biomolecules, such as amino acids, on the biomineralization process remains poorly understood. This work demonstrates the extracellular production of welldispersed copper nanoparticles by using biomass-free ureagrown Neurospora crassa growth supernatants. The nanoparticles exhibited a spherical morphology with a mean diameter around $25 \mathrm{~nm}$, which was much lower than inorganically synthesized particles or particles produced solely in the presence of amino acids. Eleven different amino acids were secreted by Neurospora crassa, and among these, glutamic acid was found to stabilize the particles in the early phase of growth and prevented them from aggregating, even at a low concentration $(1 \mathrm{mM})$. FTIR revealed the molecular interaction of amino acids and copper minerals, confirming the association of organic substances secreted by the fungus into the mineral structure. Thermal treatment of copper carbonate biominerals also suggested a facile method for producing $\mathrm{Cu}, \mathrm{Cu}_{2} \mathrm{O}$ and $\mathrm{Cu}_{2} \mathrm{~S}$ mineral products. Overall, this work provides further understanding of the potential application of fungal system for nanoparticle synthesis, the significance of amino acids in microbially induced carbonate biomineralization and possible means of controlling particle size and aggregation, and the further production of useful metal and biomineral products.
Acknowledgements Financial support in the author's laboratory is received from the Natural Environment Research Council (NE/M010910/ 1 (TeaSe); NE/M011275/1 (COG3)) which is gratefully acknowledged. We also acknowledge financial support from the China Scholarship Council through a PhD scholarship to F.L. (No. 201609110150). The authors gratefully appreciate the help of Dr. Yongchang Fan (Materials and Photonics Systems Group, University of Dundee, Dundee, UK) for assistance with scanning electron microscopy, Dr. Paul F. Schofield (Department of Mineralogy, Natural History Museum, London, UK) for assistance with X-ray powder diffraction, Dr. Peter Taylor (School of Life Sciences, University of Dundee, Dundee, UK) for assistance with highperformance liquid chromatography, and Dr. Steve M. Francis (School of Chemistry, University of St Andrews, St Andrews, UK) for assistance with X-ray photoelectron spectroscopy as well as Dr. Jean Robertson (The James Hutton Institute, Aberdeen, UK) for assistance with Fourier-transform infrared spectroscopy.

\section{Compliance with ethical standards}

Conflict of interest The authors declare that they have no conflict of interest.

Ethical statement This article does not contain any studies with human participants or animals performed by any of the authors.

Open Access This article is distributed under the terms of the Creative Commons Attribution 4.0 International License (http:// creativecommons.org/licenses/by/4.0/), which permits unrestricted use, distribution, and reproduction in any medium, provided you give appropriate credit to the original author(s) and the source, provide a link to the Creative Commons license, and indicate if changes were made.

\section{References}

Adamczyk Z, Weroński P (1999) Application of the DLVO theory for particle deposition problems. Adv Colloid Interf Sci 83(1):137-226

Berthon G (1995) Stability constants of metal complexes of amino acids with charged side chains-part I: positively charged side chains (Technical Report. Pure Appl Chem 67(7):1117-1240

Biesinger MC (2017) Advanced analysis of copper X-ray photoelectron spectra. Surf Interface Anal 49(13):1325-1334

Braissant O, Cailleau G, Dupraz C, Verrecchia EP (2003) Bacterially induced mineralization of calcium carbonate in terrestrial environments: the role of exopolysaccharides and amino acids. J Sediment Res 73(3):485-490

Briegel C, Seto J (2012) Single amino acids as additives modulating $\mathrm{CaCO}_{3}$ mineralization. Adv Topics Biomineral:33-48

Byrne J, Telling N, Coker V, Pattrick R, Van Der Laan G, Arenholz E, Tuna F, Lloyd J (2011) Control of nanoparticle size, reactivity and magnetic properties during the bioproduction of magnetite by Geobacter sulfurreducens. Nanotechnology 22(45):455709

Castro-Longoria E, Vilchis-Nestor AR, Avalos-Borja M (2011) Biosynthesis of silver, gold and bimetallic nanoparticles using the filamentous fungus Neurospora crassa. Colloids Surf B: Biointerfaces 83(1):42-48

Cedzynska K, Langfelderová H, Gažo J (1981) Factors affecting copper (II) reduction in aqueous solutions containing glycine. Chem Pap 35(2):223-228

Choi SH, An K, Kim EG, Yu JH, Kim JH, Hyeon T (2009) Simple and generalized synthesis of semiconducting metal sulfide nanocrystals. Adv Funct Mater 19(10):1645-1649 
Dabera GDMR, Walker M, Sanchez AM, Pereira HJ, Beanland R, Hatton RA (2017) Retarding oxidation of copper nanoparticles without electrical isolation and the size dependence of work function. Nat Commun 8(1): 1894

Ding Z, Frost RL, Kloprogge JT (2002) Thermal activation of copper carbonate. J Mater Sci Lett 21(13):981-983

Frost RL, Ding Z, Kloprogge JT, Martens WN (2002) Thermal stability of azurite and malachite in relation to the formation of mediaeval glass and glazes. Thermochim Acta 390(1-2):133-144

Gadd GM (2007) Geomycology: biogeochemical transformations of rocks, minerals, metals and radionuclides by fungi, bioweathering and bioremediation. Mycol Res 111(1):3-49

Gadd GM (2010) Metals, minerals and microbes: geomicrobiology and bioremediation. Microbiology 156(3):609-643

Gadd GM, Raven JA (2010) Geomicrobiology of eukaryotic microorganisms. Geomicrobiol J 27(6-7):491-519

Gawande MB, Goswami A, Felpin FX, Asefa T, Huang X, Silva R, Zou X, Zboril R, Varma RS (2016) $\mathrm{Cu}$ and Cu-based nanoparticles: synthesis and applications in catalysis. Chem Rev 116(6):3722-3811

Ghadiri M, Chrzanowski W, Lee WH, Rohanizadeh R (2014) Layered silicate clay functionalized with amino acids: wound healing application. RSC Adv 4(67):35332-35343

Hochella MF, Lower SK, Maurice PA, Penn RL, Sahai N, Sparks DL, Twining BS (2008) Nanominerals, mineral nanoparticles, and earth systems. Science 319(5870):1631-1635

Jack KS, Vizcarra TG, Trau M (2007) Characterization and surface properties of amino-acid-modified carbonate-containing hydroxyapatite particles. Langmuir 23(24):12233-12242

Jiang W, Pacella MS, Athanasiadou D, Nelea V, Vali H, Hazen RM, Gray JJ, McKee MD (2017) Chiral acidic amino acids induce chiral hierarchical structure in calcium carbonate. Nat Commun 8:15066. https://doi.org/10.1038/ncomms15066

Kimber Richard L, Lewis Edward A, Parmeggiani F, Smith K, Bagshaw H, Starborg T, Joshi N, Figueroa Adriana I, van der Laan G, Cibin G, Gianolio D, Haigh Sarah J, Pattrick Richard AD, Turner Nicholas J, Lloyd Jonathan R (2018) Biosynthesis and characterization of copper nanoparticles using Shewanella oneidensis: application for click chemistry. Small 14(10):1703145

Kryukova NP, Frolov VY, Kolokolov FA, Bolotin SN, Panyushkin VT (2005) Synthesis and study of copper (II) complexes with aspartic acid, serine, and valine. Russ J Gen Chem 75(4):503-506

Kwon SG, Hyeon T (2008) Colloidal chemical synthesis and formation kinetics of uniformly sized nanocrystals of metals, oxides, and chalcogenides. Acc Chem Res 41(12):1696-1709

Li Q, Gadd GM (2017) Biosynthesis of copper carbonate nanoparticles by ureolytic fungi. Appl Microbiol Biotechnol 101(19):7397-7407

Li Q, Csetenyi L, Gadd GM (2014) Biomineralization of metal carbonates by Neurospora crassa. Environ Sci Technol 48(24):14409-14416

Li Q, Csetenyi L, Paton GI, Gadd GM (2015) $\mathrm{CaCO}_{3}$ and $\mathrm{SrCO}_{3}$ bioprecipitation by fungi isolated from calcareous soil. Environ Microbiol 17(8):3082-3097

Liu G, Huang Y, Qu X, Xiao J, Yang X, Xu Z (2016) Understanding the hydrophobic mechanism of 3-hexyl-4-amino-1, 2, 4-triazole-5thione to malachite by ToF-SIMS, XPS, FTIR, contact angle, zeta potential and micro-flotation. Colloids Surf A Physicochem Eng Asp 503:34-42

Mann S (2001) Biomineralization: principles and concepts in bioinorganic materials chemistry, vol 5. Oxford University Press, Oxford

Meng FL, Zhong HX, Zhang Q, Liu KH, Yan JM, Jiang Q (2017) Integrated $\mathrm{Cu}_{3} \mathrm{~N}$ porous nanowire array electrode for highperformance supercapacitors. J Mater Chem A 5(36):18972-18976
Navarrete JT, Hernandez V, Ramirez FJ (1994) Ir and Raman spectra of L-aspartic acid and isotopic derivatives. Biopolymers 34(8):10651077

Ngwenya BT, Magennis M, Podda F, Gromov A (2014) Self-preservation strategies during bacterial biomineralization with reference to hydrozincite and implications for fossilization of bacteria. J Royal Soc Interfaces 11(100):20140845

Opazo C, Barría MI, Ruiz FH, Inestrosa NC (2003) Copper reduction by copper binding proteins and its relation to neurodegenerative diseases. Biometals 16(1):91-98

Patterson AL (1939) The Scherrer formula for X-ray particle size determination. Phys Rev 56(10):978-982

Pawlukojć A, Leciejewicz J, Ramirez-Cuesta AJ, Nowicka-Scheibe J (2005) L-cysteine: neutron spectroscopy, Raman, IR and ab initio study. Spectrochim Acta A Mol Biomol Spectrosc 61(11-12):2474-2481

Peng Y, Shang L, Cao Y, Waterhouse GIN, Zhou C, Bian T, Wu L-Z, Tung C-H, Zhang T (2015) Copper (I) cysteine complexes: efficient earth-abundant oxidation co-catalysts for visible light-driven photocatalytic $\mathrm{H}_{2}$ production. Chem Commun 51(63):12556-12559

Poncet N, Mitchell FE, Ibrahim AF, McGuire VA, English G, Arthur JS, Shi YB, Taylor PM (2014) The catalytic subunit of the system L1 amino acid transporter (slc7a5) facilitates nutrient signalling in mouse skeletal muscle. PLoS One 9(2):e89547

Rigo A, Corazza A, di Paolo ML, Rossetto M, Ugolini R, Scarpa M (2004) Interaction of copper with cysteine: stability of cuprous complexes and catalytic role of cupric ions in anaerobic thiol oxidation. J Inorg Biochem 98(9):1495-1501

Rodante F, Marrosu G (1990) Thermal analysis of some $\alpha$-amino acids using simultaneous TG-DSC apparatus. The use of dynamic thermogravimetry to study the chemical kinetics of solid state decomposition. Thermochim Acta 171:15-29

RodrIguez-Clemente R, Serna CJ, Ocaña M, Matijević E (1994) The relationship of particle morphology and structure of basic copper (II) compounds obtained by homogeneous precipitation. J Cryst Growth 143(3-4):277-286

Saha B, Das G (2009) Malachite nanoparticle: a new basic hydrophilic surface for $\mathrm{pH}$-controlled adsorption of bovine serum albumin with a high loading capacity. J Phys Chem C 113(35):15667-15675

Saikia J, Sikdar Y, Saha B, Das G (2013) Malachite nanoparticle: a potent surface for the adsorption of xanthene dyes. J Environ Chem Eng 1(4):1166-1173

Sóvágó I, Kállay C, Várnagy K (2012) Peptides as complexing agents: factors influencing the structure and thermodynamic stability of peptide complexes. Coord Chem Rev 256(19-20):2225-2233

Stoch J, Gablankowska-Kukucz J (1991) The effect of carbonate contaminations on the XPS O 1s band structure in metal oxides. Surf Interface Anal 17(3):165-167

Süsse P (1967) Verfeinerung der kristallstruktur des malachits, $\mathrm{Cu}_{2}(\mathrm{OH})_{2} \mathrm{CO}_{3}$. Acta Crystallogr 22(1):146-151

Tawil N, Sacher E, Boulais E, Mandeville R, Meunier M (2013) X-ray photoelectron spectroscopic and transmission electron microscopic characterizations of bacteriophage-nanoparticle complexes for pathogen detection. J Phys Chem C 117(40):20656-20665

Thakkar KN, Mhatre SS, Parikh RY (2010) Biological synthesis of metallic nanoparticles. Nanomed Nanotechnol 6(2):257-262

Thanh NT, Maclean N, Mahiddine S (2014) Mechanisms of nucleation and growth of nanoparticles in solution. Chem Rev 114(15):7610 7630

Tourney J, Ngwenya BT (2014) The role of bacterial extracellular polymeric substances in geomicrobiology. Chem Geol 386:115-132

Valentine JS, Gralla EB (2002) Advances in protein chemistry: coppercontaining proteins. Academic, Cambridge 
Wagner CD, Zatko DA, Raymond RH (1980) Use of the oxygen KLL Auger lines in identification of surface chemical states by electron spectroscopy for chemical analysis. Anal Chem 52(9):1445-1451

Wang Z, Xu Z, Zhao W, Sahai N (2015) A potential mechanism for amino acid-controlled crystal growth of hydroxyapatite. J Mater Chem B 3(47):9157-9167

Wolthers M, Charlet L, Van Cappellen P (2008) The surface chemistry of divalent metal carbonate minerals; a critical assessment of surface charge and potential data using the charge distribution multi-site ion complexation model. Am J Sci 308(8):905-941

Xu J, Xue D (2005) Fabrication of malachite with a hierarchical spherelike architecture. J Phys Chem B 109(36):17157-17161

Xu X, Xia L, Huang Q, Gu J-D, Chen W (2012) Biosorption of cadmium by a metal-resistant filamentous fungus isolated from chicken manure compost. Environ Technol 33(14):1661-1670
Zare D, Khoshnevisan K, Barkhi M, Tahami HV (2013) Fabrication of capped gold nanoparticles by using various amino acids. J Exp Nanosci 9(9):957-965

Zhang Y, Ni Y, Ye S (2016) Spherical CuO superstructures originating from hierarchical malachite microspheres by different posttreatment routes: a comparison study of the morphology and the catalytic property. RSC Adv 6(9):7086-7092

Publisher's note Springer Nature remains neutral with regard to jurisdictional claims in published maps and institutional affiliations. 